\title{
Presentation and progress of childhood diabetes mellitus: a prospective population-based study
}

\author{
J.H.Pinkney ${ }^{1}$, P.J. Bingley ${ }^{1}$, P. A. Sawtell ${ }^{1}$, D. B. Dunger ${ }^{2}$, E. A. M. Gale ${ }^{1}$, The Bart's-Oxford Study Group* \\ ${ }^{1}$ Department of Diabetes and Metabolism, St Bartholomew's Hospital, London, UK \\ ${ }^{2}$ Department of Paediatrics, John Radcliffe Hospital, Oxford, UK
}

Summary We surveyed the clinical presentation, initial management and subsequent course of a prospectively registered, population-based cohort of 230 patients with Type 1 (insulin-dependent) diabetes mellitus diagnosed before age 21 years in the Oxford Regional Health Authority area in 1985 and 1986. Clinical details from the time of diagnosis were available on 219 patients. Thirty-four $(16 \%)$ were in severe ketoacidosis with $\mathrm{pH}$ less than 7.10 or plasma bicarbonate less than $10 \mathrm{mmol} / \mathrm{l}$, and $21(10 \%)$ had mild to moderate ketoacidosis with $\mathrm{pH} 7.10-7.35$ or plasma bicarbonate 10 $21 \mathrm{mmol} / \mathrm{l}$. One child died in ketoacidosis. Presentation in severe ketoacidosis was most common in children under age 5 years $(p<0.05)$, and ketoacidosis of any degree was less frequent in older children $(0.05<$ $p<0.01$ ) and those with a parent or sibling with diabetes $(p<0.01)$. Within 4 years of diagnosis, 55 of 211 patients $(26 \%)$ experienced severe hypoglycaemia, which in $31(15 \%)$ led to one or more admissions. Readmission for unstable glycaemic control excluding acute hypoglycaemia occurred at least once within 1 year of diagnosis in $13 \%$ and within 4 years in $28 \%$, and was more common in girls, in children aged less than 10 years at diagnosis, and those with a history of severe hypoglycaemia. A second cohort of 97 similar patients was recruited in 1990. The rates of admission at diagnosis $(79 \%)$, severe ketoacidosis $(13 \%)$ and mild to moderate ketoacidosis $(13 \%)$ did not differ from the 1985/1986 cohort. Despite recent developments in diabetes management and a high level of clinical commitment at participating centres, ketoacidosis remains a common presentation of childhood diabetes, and hypoglycaemia is unacceptably frequent in the years following diagnosis. Greater public and medical awareness of the presenting features of diabetes in young children is needed to reduce the frequency of ketoacidosis at presentation, while hypoglycaemia remains a major obstacle to good glycaemic control. [Diabetologia (1994) 37: 70-74]

Key words Type 1 (insulin-dependent) diabetes mellitus, clinical presentation, ketoacidosis, hypoglycaemia.
A large prospective, population-based family study of childhood diabetes mellitus has been running in the Oxford region in southern England since 1985, with a high level of ascertainment of new cases drawn from a background population of 2.4 million, served by eight health districts [1]. The Oxford region has a long tradition of diabetes research. The outcome of diabetic ke-

* see Acknowledgements

Received: 16 April 1993

and in revised form: 9 July 1993

Corresponding author: Professor E. A. M. Gale, Department of Diabetes and Metabolism, St Bartholomew's Hospital, London EC1 A $7 \mathrm{BE}, \mathrm{UK}$ toacidosis in Oxford is known for the years 1931-1950 [2], as is the frequency of hospital admission for children with diabetes in Oxford from 1969-1976 [3], and the presenting features of newly-diagnosed diabetes from 1972-1975 were reported in two hospitals serving one of the health districts covered by the present survey [4]. These studies provide a useful "yardstick" against which to measure current experience.

We surveyed the clinical presentation, initial management and subsequent course of those diagnosed in 1985 and 1986, and compared presenting features and management with those of a cohort recruited in 1990. The aims were (1) to establish the frequency of presentation in ketoacidosis - particularly in the light of recent claims that this is becoming less common [5]-(2) 
Table 1. Patient characteristics

\begin{tabular}{lll}
\hline & $1985 / 1986$ cohort & 1990 cohort \\
\hline Total $(n)$ & 230 & 97 \\
$\begin{array}{l}\text { Male: Female } \\
\begin{array}{l}\text { Age at diagnosis (years) } \\
\text { (mean } \pm \text { SD) }\end{array}\end{array}$ & $130: 100$ & $58: 39$ \\
$\begin{array}{l}\text { Number admitted to } \\
\text { hospital at diagnosis }\end{array}$ & $182(79 \%)$ & $77(79 \%)$ \\
\hline
\end{tabular}

to find how many children started on insulin as out-patients, and whether this appeared to influence their subsequent progress, and (3) to determine the frequency of readmission and severe hypoglycaemia over the first 4 years of diabetes.

\section{Patients and methods}

\section{Patients}

Two hundred and thirty patients were identified in whom insulin-dependent diabetes was diagnosed under the age of 21 years between 1 January 1985 and 31 December 1986, and who lived in the Oxford region of southern England at the time of diagnosis. Case ascertainment levels were greater than $95 \%$ [1]. One hundred and seventy-four $(74 \%)$ of the patients and their families have been prospectively followed in the Bart's-Oxford study. One child died 4 days after diagnosis. An additional 97 patients with insulin-dependent diabetes diagnosed between 1 January 1990 and 31 December 1990 were identified by prospective registration. Case ascertainment in the 1990 cohort has not as yet been validated from other sources.

\section{Collection of data}

(i) Questionnaires. The families of patients from the 1985/1986 cohort who were under prospective follow-up were contacted by home visits or by telephone in 1988 and again in April 1991; 161 families answered one or both questionnaires. They were asked about admission to hospital at diagnosis, use of intravenous insulin or fluids, whether insulin had been discontinued at any time, details of all hospital admissions over the 4 years following diagnosis, and all episodes of hypoglycaemia resulting in unconsciousness, hospital admission or requiring parenteral glucose or glucagon. For the 1990 cohort details of initial hospital admission and intravenous therapy were recorded by questionnaire at entry into the Bart's-Oxford prospective study.

(ii) Review of medical records. Medical records were examined for all patients whose parents reported intravenous treatment on admission. In addition, medical records were reviewed on a sample of 33 of the $96(34 \%)$ whose parents reported admission but no intravenous therapy, and on 57 of the 69 members of the $1985 / 1986$ cohort who had not been included in the Bart's-Oxford study or who did not respond to the questionnaire. A total of 155 of $230(67 \%$ ) sets of records for the $1985 / 1986$ cohort were reviewed and the following information recorded: whether or not admission occurred at diagnosis, details of intravenous therapy, blood glucose, urea, acid-base status, subsequent insulin requirements, hospital admissions; and episodes of severe hypoglycaemia. Serial measures of glycated haemoglobin or fructos- amine were recorded from all available notes, and from central laboratory records in three of ten hospitals. For the 1990 cohort, notes were reviewed if the questionnaire indicated admission and intravenous therapy, if this point was not clear, or if they refused or were ineligible for recruitment into the Bart's-Oxford study. The notes of two of these patients could not be traced.

(iii) Classification of acid-base data. Ketoacidosis was classified as severe $(\mathrm{pH}<7.1$ or bicarbonate $<10.0 \mathrm{mmol} / 1)$, moderate (pH 7.1-7.25, or bicarbonate $10.0-15.0 \mathrm{mmol} / \mathrm{l})$, or mild $(\mathrm{pH}$ $7.25-7.35$ or bicarbonate $15.1-21.0 \mathrm{mmol} / \mathrm{l}$ ) [6].

Venous bicarbonate was recorded in 82 of the 115 patients from both cohorts in whom acid-base data were available, and arterial puncture was performed in the remaining 33 patients.

\section{Validation of questionnaire methods}

Responses to questions concerning hospital admission and intravenous therapy were checked with a sample of 33 hospital records. In all instances the information in the notes matched that obtained by questionnaire, and the families of all 15 patients admitted at diagnosis accurately recalled whether intravenous therapy had been given. Conversely, confirmation was possible for 47 out of a sample of 50 patients who had reported receiving intravenous therapy. As expected, intravenous therapy was given in all cases of severe diabetic ketoacidosis, and was omitted in only seven of those with mild to moderate ketoacidosis, indicating that few cases were missed by our questionnaire.

\section{Statistical analysis}

Age at diagnosis was classified as 0-4, 5-9, 10-14, and 1521 years, and acid-base data were stratified as described above. Chi-squared tests were used to compare discrete variables and stratified data and to assess trends. Ages were compared by Mann-Whitney U test.

\section{Results}

Sex, age, and whether admitted to hospital at diagnosis were known in all 230 members of the $1985 / 1986$ cohort. Further information concerning readmission $(n=212)$ and hypoglycaemia $(n=211)$ was obtained by questionnaire or from the notes. Thirty-seven patients had either withdrawn from the study, moved out of the area or been lost to follow-up during the study period, and follow-up was incomplete for 15 patients. Table 1 shows the characteristics of the 1985/1986 and 1990 patient cohorts. There was no difference in sex ratio but the mean age at diagnosis was significantly lower in the 1990 cohort $(9.4 \pm 4.9$ vs $12.4 \pm 5.5$ years, $p<0.001)$.

\section{Presentation}

Table 2 summarizes the data concerning clinical presentation. Patients who were admitted to hospital were significantly younger than those not admitted in both the $1985 / 1986(11.5 \pm 4.7$ vs $15.6 \pm 4.4$ years, $p<0.001)$ 
Table 2. Frequency of diabetic ketoacidosis at diagnosis

\begin{tabular}{|c|c|c|c|c|c|}
\hline Patient age group & $n^{\mathbf{a}}$ & $\begin{array}{l}\text { Not admitted, no IVI, } \\
\text { or no DKA }\end{array}$ & Mild DKA & Moderate DKA & Severe DKA \\
\hline \multicolumn{6}{|l|}{$1985 / 1986$ cohort } \\
\hline \multicolumn{6}{|l|}{1990 cohort } \\
\hline $\begin{array}{c}0-4 \text { years } \\
5-9 \text { years } \\
10-14 \text { years } \\
15-21 \text { years }\end{array}$ & $\begin{array}{l}26 \\
24 \\
28 \\
17\end{array}$ & $\begin{array}{l}16(62 \%) \\
19(79 \%) \\
20(71 \%) \\
15(88 \%)\end{array}$ & $\begin{array}{l}2(8 \%) \\
2(8 \%) \\
1(4 \%) \\
-\end{array}$ & $\begin{array}{l}2(8 \%) \\
1(4 \%) \\
5(18 \%) \\
-\end{array}$ & $\begin{array}{l}6(23 \%) \\
2(8 \%) \\
2(7 \%) \\
2(12 \%)\end{array}$ \\
\hline
\end{tabular}

${ }^{a}$ excluding cases admitted whose notes were not traced. IVI, Intravenous infusion; DKA, diabetic ketoacidosis

Table 3. Severe hypoglycaemia over the first 4 years after diagnosis in the 1985/1986 cohort

\begin{tabular}{lcc}
\hline Patient age group & $n$ & $\begin{array}{l}\text { Any episode of severe } \\
\text { hypoglycaemia within } \\
\text { 4 years of diagnosis }\end{array}$ \\
\hline 0-4 years & 16 & $7(44 \%)$ \\
5-9 years & 47 & $15(32 \%)$ \\
10-14 years & 81 & $22(27 \%)$ \\
15-21 years & 67 & $11(16 \%)$ \\
Total & 211 & $55(26 \%)$ \\
\hline
\end{tabular}

and 1990 cohorts $(8.0 \pm 5.0$ vs $15.0 \pm 3.9$ years, $p<0.001$ ). One child died at the time of diagnosis, having presented in ketoacidotic coma. Ketoacidosis of any degree was most common in children below age 5 $(p<0.01)$ and was less common with increasing age. Severe ketoacidosis (plasma bicarbonate $<10 \mathrm{mmol} / \mathrm{l}$ or arterial $\mathrm{pH}<7.1$ ) was also more frequent in those below age 5 years $(p<0.05)$. There was no sex difference in frequency. Only 1 of $27(4 \%)$ children with a first degree relative with diabetes presented with plasma bicarbonate below $10 \mathrm{mmol} / \mathrm{l}$ compared with 28 of $151(19 \%)$ children with no family history $(p=0.05)$, and presentation with any degree of ketoacidosis was also less common in those with a family history $(p<0.01)$. Those with parents in social classes 3,4 , and 5 , were more likely to present in ketoacidosis than those in social classes 1 and $2(p<0.05)$.

\section{Progress after diagnosis}

(i) Non-insulin-requiring remission. In the $1985 / 1986$ cohort, insulin was withdrawn in only 11 of the 212 $(5 \%)$ for whom the information was obtainable. In nine children this remission lasted under one week, in one 12 days, and in another it lasted 42 days.

(ii) Readmissions to hospital after diagnosis. Of the $1985 / 1986$ cohort $14 \%$ (29 of 212) were readmitted be- tween 1 month and 1 year after diagnosis for poorlycontrolled diabetes including ketoacidosis, $15 \%$ ( 32 of 210 ) within 2 years and $22 \%$ (43 of 197) within 4 years. A total of 154 admissions were recorded between 1 month and 4 years from diagnosis. The risk of admission was 0.27 per patient-year between 1 month and 1 year, and 0.19 per patient-year within 4 years of diagnosis. Admission for poor glycaemic control was more common in girls $(44 \%$ vs $19 \%, p<0.001)$ and admission within 2 years of diagnosis was more common in younger children $(p<0.05)$. There was no relationship between admissions for poor diabetic control and family history of diabetes, social class, original presentation in ketoacidosis, admission or intravenous treatment at the time of diagnosis.

(iii) Severe hypoglycaemia. In 55 (26\%) of the patients, episodes of severe hypoglycaemia were reported within 4 years of diagnosis and in $31(15 \%)$ this resulted in hospital admission (Table 3). This was more common in younger children, but there was norelationship with sex, family history of diabetes, social class, or with ketoacidosis or hospital admission at the original presentation. Episodes of severe hypoglycaemia were, however, more common in those readmitted for hyperglycaemia or ketoacidosis. Of those 55 patients reporting severe hypoglycaemia, 24 (44\%) had admissions for poor control, compared with 33 of $142(23 \%)$ of the remainder $(p<0.01)$. Fifty-three admissions due to hypoglycaemia were recorded in 31 patients, giving an overall risk of $0.062 \mathrm{admissions}$ per patient-year of follow-up.

(iv) Indices of metabolic control. Serial glycated haemoglobin or fructosamine measurements, or both were available for 144 out of $230(64 \%)$ patients in the $1985 / 1986$ cohort with between 1 and 26 tests per patient (median 3). There was no relation between the mean glycated haemoglobin or fructosamine measured during follow-up and ketoacidosis, admission at diagnosis, or subsequent diabetic admissions over the follow-up period. 


\section{Discussion}

Between 1972 and 1975,26\% of children presenting to hospitals in the East Berkshire district of the Oxford Region with newly-diagnosed diabetes were in ketoacidosis with serum bicarbonate below $15 \mathrm{mmol} / \mathrm{l}$ [5]. In the same region, 10-15 years later the equivalent figures were $20.5 \%$ and $21 \%$, and one child died in ketoacidosis. There are few population-based surveys of the clinical presentation of insulin-dependent diabetes, and no standard methods of data collection or accepted definition of diabetic ketoacidosis, making it difficult to establish whether ketoacidosis is more or less frequent in the United Kingdom than elsewhere. A hospitalbased study in Finland found that $25 \%$ of children and adolescents had a capillary blood $\mathrm{pH}$ below 7.35 at diagnosis [7], very comparable to the estimates we obtained. In contrast, a recent French study found that $48 \%$ of patients with diabetes diagnosed below age 19 years and $66 \%$ of those diagnosed below age 5 had a total $\mathrm{CO}_{2}$ below $18 \mathrm{mmol} / \mathrm{l}$, and $28 \%$ were by our definition (venous bicarbonate $<10 \mathrm{mmol} / \mathrm{l}$ ) in severe ketoacidosis [8]. Further comparable studies are needed to determine whether such apparent differences are due to study methods, delay in diagnosis or true geographical differences in the disease process.

All children except one survived their first episode of ketoacidosis. Indeed, the prognosis of ketoacidosis in children has always been better than that of older patients, leading Elliott Joslin to remark that "it would almost seem as if children throve on coma". In 1926, 3 years after the introduction of insulin, he reported that 45 of 200 children (23\%), 9 newly diagnosed, had 53 episodes of "diabetic coma" without any deaths [9]. Even so, one avoidable death in childhood is still too many, and ketoacidosis is largely responsible for the reported 0.4 to $0.9 \%$ mortality among children at diagnosis [10]. Early diagnosis, rather than improved hospital management, must offer the best hope of reducing this risk.

Prospective study has shown that glucose intolerance often develops slowly and well in advance of clinical symptoms in children developing diabetes [11]. Ketoacidosis is a late feature and potentially avoidable by early diagnosis and insulin therapy. In one study, at least $70 \%$ of children had symptoms for more than 2 weeks before admission, and $44 \%$ for more than a month. As many as $47 \%$ had seen their general practitioner more than once before the diagnosis was made, including 11 of 17 who presented in ketoacidosis [4]. Diabetes remains an uncommon disease in childhood a general practitioner in the Oxford region might only expect to see a new case every 12 years - but it has probably doubled in incidence in many European countries over the past 20 years [12]. The rising incidence may be most marked in children under age 5 [13], in whom clinical presentation is more acute [14], and early diagnosis in this age group may be particularly difficult. Nevertheless in one-third of cases the diagnosis may already be suspected by the family before they seek medical help [5]. A high level of awareness by the family increases the chance of early diagnosis as demonstrated by the low rate of presentation in ketoacidosis in children with a family history of insulin-dependent diabetes. Increased public awareness, and greater medical alertness to early and sometimes non-specific manifestations of insulin-dependent diabetes, might well reduce the frequency and severity of ketoacidosis in young children.

During 1985 and 1986, 79\% of new cases were admitted. The proportion of patients admitted at diagnosis varied from $48-100 \%$ between districts, and two of the eight districts accounted for $48 \%$ of all those not admitted. Our study confirmed that admission at diagnosis does not affect subsequent outcome measures such as readmission or episodes of severe hypoglycaemia, even when the groups were matched for severity of disease at presentation $[6,15]$. A survey of British paediatricians found that $87 \%$ admitted more than $80 \%$ of all new cases, but that $47 \%$ would change this policy if better community facilities became available [16]. At present, the majority of paediatricians in the Oxford Region continue to favour a brief admission at diagnosis unless the family have previous knowledge of insulin-dependent diabetes.

Diabetes disrupts the life of children and their families. Of those children diagnosed in 1985-1986 $38 \%$ had subsequent diabetes-related hospital admissions within 4 years. The overall rate of hospitalization was 0.26 admissions per patient-year; 0.19 per patientyear for poor glycaemic control and 0.06 per patientyear for hypoglycaemia. These rates have changed little since 1973-1976 [3]. This type of estimate can however be distorted by recurrent admissions, and we found that $33 \%$ of the recorded readmissions (37 of 112 ) within 2 years of diagnosis were due to two individual patients! In a population-based study in Rhode Island (USA), $25 \%$ of children under 10 years of age and $13 \%$ of those aged between 10 and 19 were readmitted at least once within 1 year of diagnosis [17]. Girls are more likely to be readmitted than boys but the relationship with age at diagnosis is inconsistent. We found younger children to be at highest risk whereas Haman et al. [6] found the risk highest in adolescence, and Hardie et al. [3] found no relationship with age.

One-fourth of the patients diagnosed in 1985 and 1986 reported at least one episode of severe hypoglycaemia resulting in coma or requiring parenteral treatment with glucose or glucagon within 4 years of diagnosis. The average incidence of $6.5 \%$ per year is strikingly similar to that of two recent surveys in childhood diabetes $[18,19]$, and considerably lower than that in two others $[20,21]$ (Table 4), but these rates are notoriously difficult to compare. Egger et al. [18] reported a rising incidence of severe hypoglycaemia in a Swiss paediatric diabetic clinic, from 4.4 per 100 patient years from 1981 to 1984 to 7.4 per 100 patient years from 1985 to 1988 . This increase corresponded to a change to intensified insulin therapy, and lower mean $\mathrm{HbA}_{1}$ levels. 
Table 4. Recent studies of severe hypoglycaemia in childhood diabetes

\begin{tabular}{lcc}
\hline & $n$ & $\begin{array}{c}\text { Average incidence } \\
\text { of severe hypogly- } \\
\text { caemia (\%/year) }\end{array}$ \\
\hline Oxford (UK) 1985-1990 & 210 & $6.5^{\mathrm{a}, \mathrm{b}}$ \\
Berne (Switzerland) 1981-1984 [18] & 155 & $5.9^{\mathrm{a}}$ \\
Berne (Switzerland) 1985-1988 [18] & 155 & $7.4^{\mathrm{a}}$ \\
Montreal (Canada) [19] & 350 & $6.8^{\mathrm{a}}$ \\
Toronto (Canada) 1986 [20] & 311 & $16.0^{\mathrm{a}}$ \\
Örebro (Sweden) 1986 [21] & 92 & $20.0^{\mathrm{b}}$
\end{tabular}

Severe hypoglycaemia was defined as a coma/convulsions; or ${ }^{\mathrm{b}}$ requiring glucagon or i.v. glucose

Our findings suggest that a high rate of hypoglycaemia is the price that must be paid for the current emphasis on strict glycaemic control.

One in four children with newly-diagnosed diabetes still present in ketoacidosis, despite advances in diabetes care and management. The incidence of insulin-dependent diabetes seems to be rising most rapidly in the under 5 age group, and ketoacidosis is common, severe and occasionally fatal in the very young. Since diabetes is easy to diagnose once suspected, greater awareness among family doctors and the public could reduce the scale of this problem. Readmission to hospital is necessary in $38 \%$ of children over the first 4 years of the disease, and $26 \%$ of children experience episodes of severe hypoglycaemia within 4 years of starting insulin therapy. It is cause for particular concern that these findings come from a region of the United Kingdom notable for its high level of health care provision, and with a tradition of enthusiasm and commitment for the care of diabetes in children. There have been many important developments in diabetes care over the past 15 years, including improved education, provision of diabetes nurse specialists, home blood glucose monitoring, availability of glucose meters in general practitioner's surgeries, pen injection devices and multiple injection regimens, but the likelihood of presentation in ketoacidosis remains high, and the risk of severe hypoglycaemia may have increased. This survey has provided the impetus for a regional audit of the provision and delivery of paediatric diabetic care, and this process may help to reduce the frequency of these complications. The need is urgent since the first years of diabetes probably determine the impact of the disease upon the rest of a child's life.

Acknowledgements. We would like to thank all the families participating in the Bart's-Oxford family study for their continuing support, and our fieldworkers, Ms M.Keggin, D.Morgans, $\mathrm{S}$. Wall and S.Jones for help in data collection. The Bart's-Oxford Study Group has the following members: Aylesbury: RS Brown, AH Knight; Banbury: RAF Bell; East Berkshire: RDM Scott; Kettering: AR Davidson, B O'Malley; Milton Keynes: PJ Latham, RC Paton; Northampton: CJ Fox, NK Griffin; Oxford: DB Dunger; Reading: NP Mann, H Simpson; Wycombe: $\mathrm{CH}$ Cheetham, L Sandler, T Westcott. The Bart's-Oxford Family Study is supported by a research grant from the British Diabetic Association.

\section{References}

1. Bingley PJ, Gale EAM (1989) The incidence of insulin-dependent diabetes in England: a study in the Oxford region 1985-6. BMJ 298: 558-560

2. Pease JC, Cooke AM (1951) The family doctor and diabetic coma. BMJ ii: $336-338$

3. Hardie J, McPherson K, Baum JD (1979) Hospital admission rates of diabetic children. Diabetologia 16:225-228

4. Hamilton DV, Mundia SS, Lister J (1976) Mode of presentation of juvenile diabetes. BMJ ii: 211-212

5. Pozzilli P, Andreani D (1990) Type 1 diabetes at presentation: the scene changes. Diabetic Med 7: 762-763

6. Hamman RD, Cook M, Keffer S et al. (1985) Medical care patterns at the onset of insulin-dependent diabetes mellitus; association with severity and subsequent complications. Diabetes Care 8 [Suppl 1]: 94-100

7. Karjalainen J, Salema P, Ilonen J, Surcel H-M, Knip M (1989) A comparison of childhood and adult type 1 diabetes mellitus. N Eng1 J Med 320: 881-886

8. Levy-Marchal C, Papoz L, de Beaufort Cet al. (1992) Clinical and laboratory features of type 1 diabetic children at time of diagnosis. Diabetic Med 9:279-284

9. Joslin EP, Root HF, White P (1927) Diabetic coma and its treatment. Med Clin N America 10: 1281-1305

10. Japan, Poland, the Netherlands, and Pittsburgh Diabetes Research Groups (1990) How frequently do children die at the onset of insulin-dependent diabetes? Analyses of registry data from Japan, Poland, the Netherlands and Allegheny County. Diab Nutr Metab 3: 57-62

11. Tarn AC, Smith CP, Spencer KM, Bottazzo GF, Gale EAM (1987) Type 1 (insulin-dependent) diabetes: a disease of slow clinical onset - ? BMJ 294:342-345

12. Bingley PJ, Gale EAM (1989) Rising incidence of IDDM in Europe. Diabetes Care 12: 289-295

13. Metcalfe MA, Baum JD (1991) Incidence of insulin dependent diabetes in children under 15 years in the British Isles during 1988. BMJ 302: 443-447

14. Jefferson IG, Smith MA, Baum JD (1985) Insulin dependent diabetes in under 5 year olds. Arch Dis Child 60:1144-1148

15. Wilson RM, Clarke P, Barkes H, Heller SP, Tattersall RB (1986) Starting insulin as an outpatient, report of 100 consecutive patients followed up for at least one year. JAMA 256: $877-880$

16. British Paediatric Association Working Party (1990) The organization of services for children with diabetes in the United Kingdom: report of the British Paediatric Association Working Party. Diabetic Med 7: 457-464

17. Fishbein HA, Faich GA, Ellis SE (1982) Incidence and hospitalization patterns of insulin-dependent diabetes mellitus. Diabetes Care 5: 630-633

18. Egger M, Gshwend S, Davey Smith G, Zuppinger K (1991) Increasing incidence of hypoglycaemic coma in children with IDDM. Diabetes Care 14: 1001-1005

19. Bergada I, Suissa S, Dufresne J, Schriffin A (1989) Severe hypoglycaemia in IDDM children. Diabetes Care 12: 239-244

20. Aman J, Karlsson I, Wranne L (1988) Symptomatic hypoglycaemia in childhood diabetes: a population-based questionnaire study. Diabetic Med 6: 257-261

21. Daneman D, Frank M, Perlamn K, Tamm J, Ehrlich R (1992) Severe hypoglycaemia in children with insulin-dependent diabetes mellitus: frequency and predisposing factors. J Pediatr 115: 681-685 